\title{
A 4-year-old with a non-tender dorsal phalangeal lump
}

Leon Mieczyslaw $\operatorname{Sergot}^{1} \cdot$ Savvas Andronikou $^{2,3} \cdot$ Simon Thomas $^{3}$

Published online: 4 November 2017

(C) ISS 2017

Keywords Pediatric $\cdot$ Radiology $\cdot$ Nora lesion $\cdot$ BPOP

\section{History}

A 4-year-old girl with no past medical history presented with a non-traumatic and non-tender firm lump on the dorsum of her right ring finger (Fig. 1). Follow-up imaging over the subsequent 3 months demonstrated an increase in size of the lesion (Fig. 2).

The diagnosis can be found at doi: https://doi.org/10.1007/s00256-0172801-8

Leon Mieczyslaw Sergot

leon.sergot@doctors.org.uk

1 University Hospitals Bristol NHS Trust, Marlborough Street, Bristol BS1 3NU, England

2 Department of Paediatric Radiology, University of Bristol, Bristol, England

3 Bristol Royal Hospital for Children, Bristol, England 


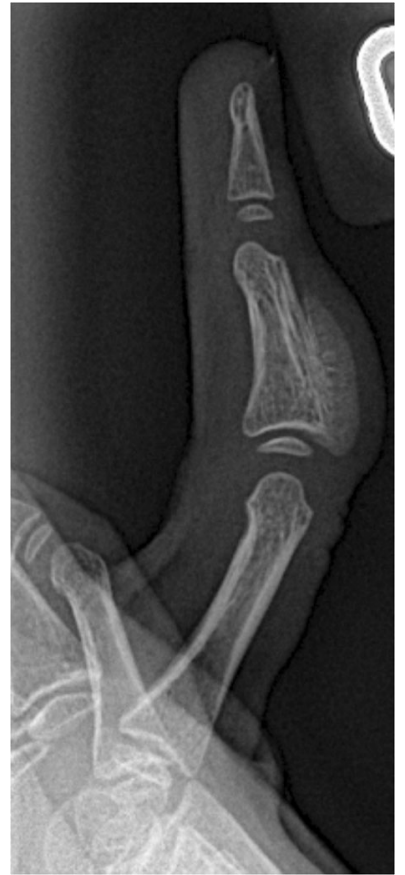

Fig. 1 Radiograph at initial presentation
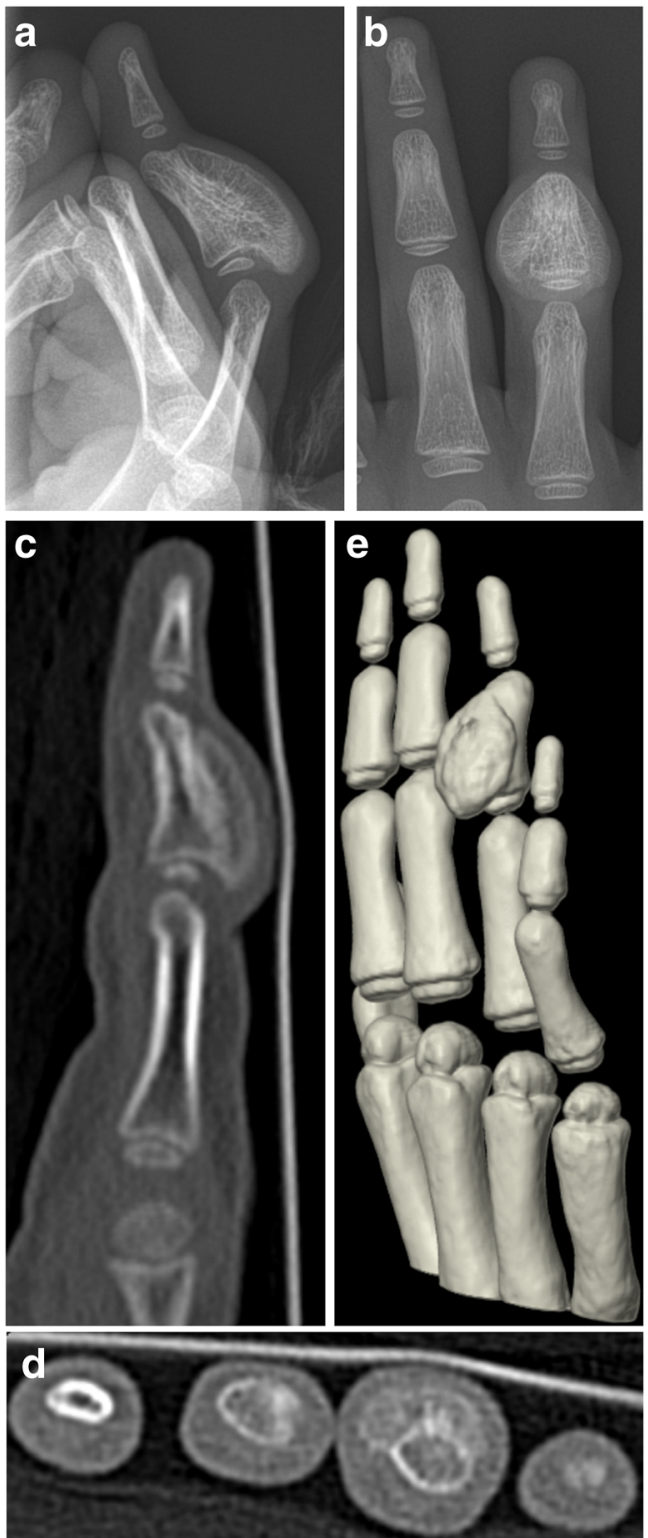

Fig. 2 a, b Radiographs and $\mathbf{c}-\mathbf{e}$ CT reconstructions at 3-month followup 